\title{
The Variation of Pre-movement Time in Building Evacuation
}

\author{
Martin Forssberg (D) and Axel Mossberg (D), Brandskyddslaget AB, Box 9196, \\ 10273 Stockholm, Sweden
}

Jesper Kjellström (D), PE Teknik \& Arkitektur AB, Södermalmsallén 36, 11828 Stockholm, Sweden

Håkan Frantzich* (D), Division of Fire Safety Engineering, Lund University, PO Box 118, 22100 Lund, Sweden

Daniel Nilsson (D), Department of Civil and Natural Resources Engineering, University of Canterbury, 69 Creyke Rd., Christchurch, New Zealand

Received: 28 June 2018/Accepted: 14 June 2019

\begin{abstract}
In order to provide a reliable evacuation design assessment, data showing the variation in pre-movement time is of vital importance. The pre-movement time is in many cases regarded as the main time period during an evacuation assessment. Therefore, forty unannounced evacuation experiments for six different occupancies were analysed to quantify pre-movement time during building evacuation, i.e., the time taken between receiving the first cue and initiation of movement towards an exit during evacuation. The occupancies were office, cinema theatres, restaurants, department stores and night clubs. The occupancies were equipped with different types of evacuation alarm systems. The study resulted in 2486 data points for the pre-movement time. The pre-movement times were matched to statistical distributions to describe the variation. It was found that the pre-movement times in most cases could be represented with a lognormal or loglogistic distribution typically having a rapid initial increase representing the phase when people start reacting, which is followed by a less steep decrease representing the phase when some people linger before evacuating. Most reliable data are provided for the cinema theatre experiments which included 1954 data points from 30 experiments. The paper also presents a structure for performing an assessment of video recorded evacuation experiment determining actions, relevant time data and fitting a statistical distribution to the data. The new information provided in the paper can help fire safety professionals to more accurately predict the time to evacuate different premises.
\end{abstract}

Keywords: Evacuation, Pre-movement time, Human behaviour, Response time, Recognition time

\section{Background}

The sequence of actions related to human behaviour in fires can traditionally be structured in four stages, known as behaviour sequences [1]. The different stages represent activities frequently occurring during an evacuation, see Fig. 1. The ini-

\footnotetext{
* Correspondence should be addressed to: Håkan Frantzich, E-mail: hakan.frantzich@brand.lth.se
} 
tial activity consists of receiving information and the subsequent stage relates to interpreting the received information. At this second stage, people can either ignore or investigate the cues. Continuing to the third stage, people prepare to act on the given information. Typically, people instruct others, investigate cues or try to see how other people respond. Finally, people evacuate the building, fight the fire, warn others or wait. This may be seen as behaviour activities leading to riskreducing actions of people in emergency situations after becoming aware of the fire threat. However, building evacuation does not follow a prescribed sequence of procedures, it is rather a dynamic process. Activities associated with different actions in the behaviour sequence does not necessarily follow a certain pattern and the process may also be repeated during an evacuation.

After the person becomes aware of the unusual situation, information is needed to confirm that there is a fire and a need for evacuation. During movement towards a safe location, new information may become available leading to a return path in the behaviour sequence to consider the new information and the implication of this. The initial phase is typically characterised by uncertainty and ambiguity as the persons are not fully aware what has actually happened. People, therefore as the first actions, try to become aware of the situation and searches for information, tries to interpret the available information and eventually prepare risk reducing measures. It is primarily evident after first having gone past the interpretation stage, i.e., people tend to act more differently when 'preparing' and 'acting' than in the interpretation stage $[1,2]$. It should be mentioned that also other theories explaining human behaviour in fires could be used to frame the work in this paper, e.g. the Protective Action Decision Model [3].

There are many factors that influence how people respond in case of a fire, i.e. what path in the behaviour sequence is actually taken. For example, social influence and group behaviour have been shown to play a major role in the early stages of evacuation $[4,5]$. This can be explained by the fact that people do not

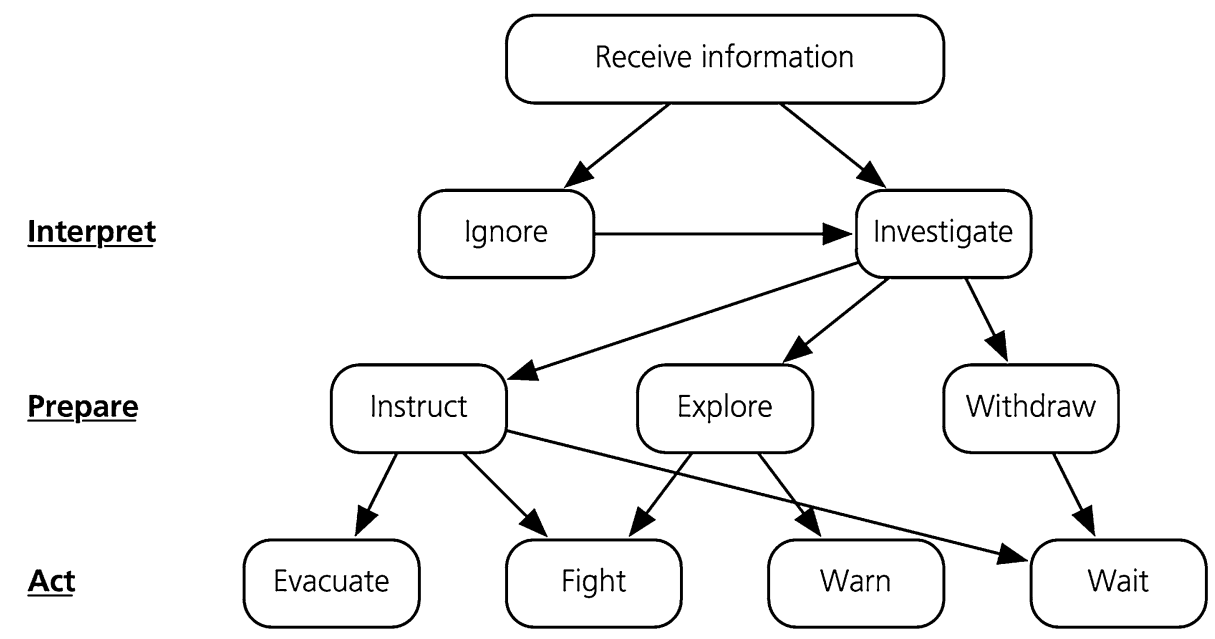

Figure 1. Sequences of human behaviour in fire according to [1]. 
want to act alone [6] or, in some cases, the influence of crowding can inhibit people from acting before others have done so [7, 8].

Another factor that has an impact on evacuation decisions is that people tend to try to find family members and friends before evacuating [9, 10]. This type of expected behaviour can be explained by the theory of affiliation [9, 11], which describes that people have a tendency to seek the familiar in uncertain emergency situation. This theory claims that people feel safer when in a known environment. The theory can also be used to explain why people choose a known evacuation route, e.g., the everyday entrance, in favour of an emergency exit located closer, and grouping behaviours, i.e., that people prefer to evacuate in groups.

Another theory that is applicable when describing human behaviour during evacuation is the role-rule model $[1,12,13]$. The behaviour of a person in a specific situation is affected by an implied set of rules connected to the everyday role of the person. The idea is that actions taken are related to the role the person has in the occupancy, rather than related to the person. Typical roles can be members of staff and customers in a shopping centre, which will lead to different behaviour and actions for the two groups.

In addition to above, one factor that has been shown to influence the behaviour of persons in the need of evacuating is the presence of an evacuation alarm, i.e. an alarm bell or a voice evacuation alarm. There are several studies on this subject [e.g. 8, 14-18]. Most often, the results from these studies show that for a public building, an informative voice alarm is the most effective type of alarm system $[7,18,19]$. However, the efficiency of interpreting the signal as related to evacuation may depend on other factors like previous knowledge of the meaning and existence of the evacuation alarm. Therefore, a simpler alarm bell used in an office environment may initiate an evacuation rapidly, i.e., the persons can be expected to know about the alarm and therefore respond quickly compared to if the same alarm bell was used in a shopping centre.

When describing evacuation of a building for engineering purposes, a simpler procedure is needed in order to be useful for an analytical treatment of the behavioural aspects during evacuation. The repeated loop through the behaviour sequence, i.e. going through the steps searching for new information and interpret information and impressions is quite complex to be manageable quantitatively when performing engineering assessments. Therefore, simpler model is used in order to assess the evacuation process when comparing to the time until untenable conditions for evacuation occurs. The evacuation process for an engineering assessment is often described using three different phases: detection, pre-movement and movement [20], each quantified as a time duration, adding up to the total evacuation time for each occupant or group of occupants. The behaviour sequence, manifested in the pre-movement phase, can be applied on different occupancies and as a foundation for an engineering approach to human behaviour during an evacuation. The sequence has since long been applied for both building and tunnel evacuation assessments, e.g. [21].

It is understood that the analytical treatment of the evacuation process, and especially the behaviour activities, is much simplified compared to actions and decisions performed during a real evacuation, and ideally there should be a clear 


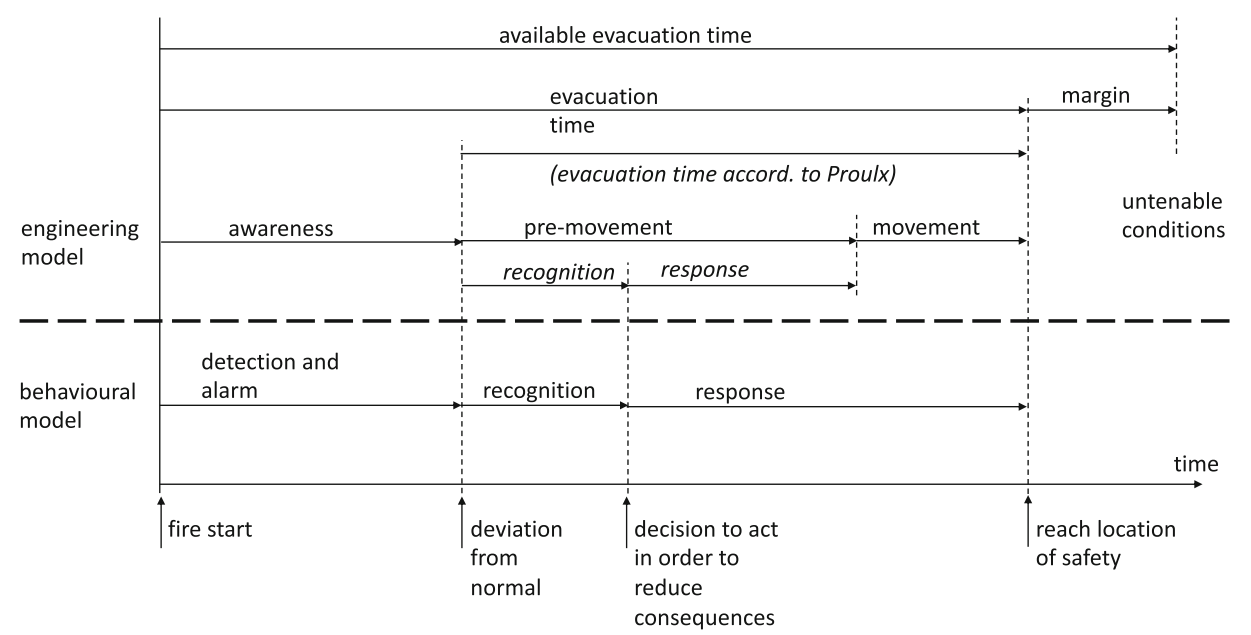

\section{Figure 2. Relation bełween engineering model for evacuation analysis and the model to explain human behaviour in fire [21].}

link between the two ways of treating evacuation, i.e., explaining evacuation behaviour and assessing evacuation during design. Therefore, two concepts are introduced in this paper to describe these two views of models; the engineering model and the behaviour model. The latter is intended to describe human behaviour actions when describing a real evacuation, still simplified compared to for example the Canter behaviour sequence model [1] explained earlier in this paper. The engineering model relates to the behavioural model, that is used to describe human behaviour in fire, as presented in Fig. 2. The important aspect in treating evacuation in these two manners is the identification of certain key events occurring in every evacuation process, all which can be identified in both models of describing evacuation behaviour.

In the figure, key events of evacuation are described and listed in the bottom line of the figure. The key events are supposed to occur simultaneously in both models making the models comparable. The key events are, at least in a theoretical sense, well-defined and occurring in every evacuation process. In engineering applications, these are often referred to by a specific time during the evacuation. Apart from the obvious ignition point, the first time of interest is when the occupant (or occupants) realises that something is different compared to a normal situation, i.e., 'deviation from normal'. At this event the occupant has become aware of something unusual, strange noise, a fire alarm, smell etc.

The next important event is when the occupant has understood that there is a hazardous situation and that something has to be done to manage the situation. The event occurs the moment the occupant decides to perform actions to reduce the consequences, either for the individual itself and/or for other occupants.

As mentioned above, human behaviour in fire in general does not necessarily follow a determined pattern even if typical behavioural sequence patterns can be identified related to for example a specific type of occupancy. Canter presents typ- 
ical sequences of behaviour for three occupancies, each having its unique sequence and hence different likely actions during the evacuation. It is, however, possible to aggregate actions into categories of behaviour. It is therefore assumed, for simplicity, that specific actions do not have to be described more accurately at this stage. The intention is to demonstrate the similarities between the two approaches, i.e., the engineering model and the behaviour model.

The main difference between the behavioural model and the engineering model is the interpretation of the response part. In the behavioural model, movement towards an exit is considered as a response, whilst movement constitutes a separate phase of the evacuation process in the engineering model. This is logical as movement is actually an activity that aims to reduce the consequences for the occupants. However, for engineering purposes it is also rational to consider movement as a separate phase as it can be modelled and used to identify movement problems, e.g., crowding influencing the subsequent behaviour. This is the current practice as there yet are no evacuation models explicitly considering human behaviour other than in a very simplistic manner.

As information related to human behaviour is a key aspect in any fire safety engineering assessment, a number of previous studies regarding evacuation behaviour are presented with respect to pre-movement time as defined according to the engineering model, see Table 1 and Fig. 2. The table illustrates a range of studies in different occupancies.

Most of the data may be used conservatively in deterministic scenario analyses. However, when performing a probabilistic assessment of building evacuation, statistical data using the representative distributions are preferred over mean values and standard deviations.

For an engineering assessment of evacuation safety, the relationship between Available Safe Egress Time (ASET) and Required Safe Egress Time (RSET) is affected by pre-movement time in a significant way [10, 23, 29]. However, it should be emphasized that simulations are simplifications of reality since the evacuation process in a particular case are influenced by factors that cannot be anticipated. Quantification of pre-movement time have varied throughout the years. Proulx [30] and Kuligowski [31] are, in their respective papers, discussing different approaches of the quantification. Most of the engineering assessments are, though, performed deterministically but the recent development in the Fire Safety Engineering community tend to focus also more on a probabilistic approach, for a better understanding of the inherent uncertainty in the assessment. In a probabilistic building design, evacuation models are used to treat evacuation scenarios more realistically. Using statistical distributions for the prediction of pre-movement time for every individual in a simulation could contribute to more realistic evacuation simulations than the deterministic approach of adding a single delay time for the entire population. This means that a more comprehensive simulation result will be achieved if each simulated individual is assigned a premovement delay based on the statistical distribution for the current occupancy, aiming at representing the expected evacuation as accurately as possible.

In order to provide additional information regarding typical behavioural conditions for evacuation assessments and providing quantitative data, a number of 


\section{Table 1}

Compilation of Pre-movement Times from Various Evacuation Experiments

\begin{tabular}{|c|c|c|c|c|c|c|}
\hline Occupancy & Mean value (s) & $\begin{array}{l}\text { Standard } \\
\text { deviation }\end{array}$ & Distribution & $\begin{array}{l}\text { Number of } \\
\text { observations }\end{array}$ & Alarm type & $\begin{array}{l}\text { Study } \\
\text { of ori- } \\
\text { gin }\end{array}$ \\
\hline \multirow[t]{3}{*}{$\begin{array}{l}\text { School }^{\mathrm{a}} \text { (University, } \\
\text { Sweden) }\end{array}$} & $32-86$ & - & - & 24 & $\begin{array}{l}\text { Voice alarm } \\
\text { (male) }\end{array}$ & [22] \\
\hline & $25-50$ & & & 8 & $\begin{array}{l}\text { Voice alarm } \\
\text { (female) }\end{array}$ & \\
\hline & $23-78$ & & & 20 & $\begin{array}{l}\text { Short voice } \\
\text { alarm } \\
\text { (male) }\end{array}$ & \\
\hline $\begin{array}{l}\text { School (University, } \\
\text { China) }\end{array}$ & 11.3 & - & Lognormal & 60 & - & [7] \\
\hline $\begin{array}{l}\text { School (University, } \\
\text { Sweden) }\end{array}$ & 40 & - & - & 187 & Voice alarm & [18] \\
\hline $\begin{array}{l}\text { School (University, } \\
\text { Italy) }\end{array}$ & 25.9 & 15.8 & Weibull & 104 & Alarm bell & [19] \\
\hline \multirow{3}{*}{$\begin{array}{l}\text { School (University, } \\
\text { Great Britain) }\end{array}$} & 35.4 & 15.8 & - & 17 & Siren & [23] \\
\hline & 22.9 & 4 & & 15 & $\begin{array}{l}\text { Informative } \\
\text { voice alarm }\end{array}$ & \\
\hline & 12.9 & 7,3 & & 16 & $\begin{array}{l}\text { Short voice } \\
\text { alarm }\end{array}$ & \\
\hline \multirow{4}{*}{$\begin{array}{l}\text { Department stores } \\
\text { (Marks \& Spen- } \\
\text { cer, Great Bri- } \\
\text { tain) }\end{array}$} & 37 & 19 & - & 570 & Alarm bell & [14] \\
\hline & 31 & 18 & & 616 & Alarm bell & \\
\hline & 25 & 14 & & 486 & Alarm bell & \\
\hline & 25 & 13 & & 409 & Alarm bell & \\
\hline \multirow{2}{*}{$\begin{array}{l}\text { Department store } \\
\text { (Marks \& Spen- } \\
\text { cer, Northern } \\
\text { Ireland) }\end{array}$} & 32 & - & Lognormal & 570 & Alarm bell & [24] \\
\hline & 36 & 15 & & 486 & Alarm bell & \\
\hline \multirow[t]{3}{*}{$\begin{array}{l}\text { Department store } \\
\text { (IKEA, Sweden) }\end{array}$} & $30,50,50$ & - & - & 160 & $\begin{array}{l}\text { Voice alarm } \\
\text { (short) }\end{array}$ & [25] \\
\hline & $27,51,31$ & & & 100 & $\begin{array}{l}\text { Voice alarm } \\
\text { (long) }\end{array}$ & \\
\hline & $26,62,83$ & & & 330 & $\begin{array}{l}\text { Voice alarm } \\
\text { (short) }\end{array}$ & \\
\hline $\begin{array}{l}\text { Grocery store (Eng- } \\
\text { land) }\end{array}$ & $\begin{array}{l}\text { Approximately } \\
20-30\end{array}$ & & Lognormal & - & $\begin{array}{l}\text { Voice } \\
\text { alarm/siren }\end{array}$ & [23] \\
\hline \multirow[t]{3}{*}{$\begin{array}{l}\text { Cinema theatre } \\
\text { (Malmö, Sweden) }\end{array}$} & Ca $15-25$ & - & - & $\begin{array}{l}\text { Total all } \\
\text { experiment: } \\
1872\end{array}$ & Alarm bell & [16] \\
\hline & Ca $15-20$ & & & & Siren & \\
\hline & $\mathrm{Ca} 25-30$ & & & & Voice alarm & \\
\hline
\end{tabular}




\section{Table 1}

\section{continued}

\begin{tabular}{|c|c|c|c|c|c|c|}
\hline Occupancy & $\begin{array}{l}\text { Mean } \\
\text { value } \\
\text { (s) }\end{array}$ & $\begin{array}{l}\text { Standard } \\
\text { deviation }\end{array}$ & Distribution & $\begin{array}{l}\text { Number of } \\
\text { observations }\end{array}$ & Alarm type & $\begin{array}{l}\text { Study } \\
\text { of ori- } \\
\text { gin }\end{array}$ \\
\hline $\begin{array}{l}\text { Cinema theatre } \\
\text { (Lund/Helsing- } \\
\text { borg, Sweden) }\end{array}$ & $30-45$ & - & - & 640 & $\begin{array}{l}\text { Variations of voice } \\
\text { alarm }\end{array}$ & {$[18]$} \\
\hline $\begin{array}{l}\text { Theatre (Kent, } \\
\text { Great Britain) }\end{array}$ & 55,6 & 24,5 & Lognormal & 338 & Voice alarm & [8] \\
\hline $\begin{array}{l}\text { Theatre (Great } \\
\text { Britain) }\end{array}$ & $\begin{array}{l}\text { Ca } 20- \\
30\end{array}$ & - & - & 300 & $\begin{array}{l}\text { Unknown } \\
\text { alarm }+ \text { manager } \\
\text { announcement }\end{array}$ & [23] \\
\hline \multirow[t]{4}{*}{$\begin{array}{l}\text { Apartments } \\
\text { (Canada) }\end{array}$} & 150 & - & - & $\begin{array}{l}\text { Average of } \\
150 \text { for the } 4 \\
\text { buildings }\end{array}$ & $\begin{array}{l}\text { Alarm bell (two } \\
\text { stage system) }\end{array}$ & [26] \\
\hline & 188 & - & - & & Alarm bell & \\
\hline & 502 & - & - & & $\begin{array}{l}\text { Alarm bell (defi- } \\
\text { cient) }\end{array}$ & \\
\hline & 582 & - & - & & $\begin{array}{l}\text { Alarm bell (defi- } \\
\text { cient) }\end{array}$ & \\
\hline $\begin{array}{l}\text { Meeting room } \\
\text { (Great Britain) }\end{array}$ & 46 & - & - & 12 & Voice alarm & [23] \\
\hline Office (Canada) & $\begin{array}{l}36 \\
63\end{array}$ & - & - & $\begin{array}{l}180 \\
500\end{array}$ & $\begin{array}{l}\text { "Good alarm" } \\
\text { "Good alarm" }\end{array}$ & [27] \\
\hline $\begin{array}{l}\text { Nightclub }^{\mathrm{d}} \text { (Lund, } \\
\text { Sweden) }\end{array}$ & $\begin{array}{l}\text { Not } \\
\text { more } \\
\text { than } 90\end{array}$ & - & - & $100-150$ & Voice alarm & [28] \\
\hline
\end{tabular}

Details of each experiment are presented in the respective paper

${ }^{a}$ Pre-movement times are presented as minimum and maximum values instead of mean values

${ }^{b}$ Department store including restaurant. Presented times refers to store area, restaurant and pay desk area. Three different stores were included in the study. Number of customers (in italic) in the store are presented, number of observations was not presented in the source

${ }^{c}$ People were told about the experiments on beforehand. For longer pre-movement time, the evacuation alarm was deficient

${ }^{\mathrm{d}}$ The evacuation process was assisted by staff. Evacuation of nightclubs is assessed to be dependent of the act of staff. No mean value is presented

previously performed unannounced evacuation experiments were re-examined. The focus in this paper is to present a structured method to analyse video recordings from evacuation experiments and to present the data on the pre-movement phase in terms of statistical distributions, not just as mean value and a standard deviation. 


\section{Method}

Video recordings from previously performed unannounced evacuation experiments were re-examined. A set of experiments were chosen considering a variation of building occupancies of interest. The experiments studied included the following occupancies:

1. Office [32]

2. Cinemas $[16,17,32]$

3. Department stores $[25,33]$

4. Restaurant/café [25]

5. University (school) [22]

6. Nightclubs [28].

In order to obtain robust analysis results, a structured procedure for identifying behavioural aspects was initially created. The procedure was used to ensure a consistent workflow. The engineering model was used throughout the analysis when identifying and quantifying the two parts of the pre-movement time.

The procedure was divided into four different steps described below.

1. Overall analysis of the evacuation scenario.

The evacuation video was watched from beginning to end to get an idea of the specific evacuation process of the experiment and to identify people in the experiments who were to be included in the analysis.

2. Detailed analysis of the evacuation scenario.

The pre-movement time, also separated into recognition time and response time (according to the engineering model), was quantified for each individual in the evacuation experiment according to the initially derived structure. This was done by two of the authors individually and documented in a spread sheet. The reason for the individual analysis by the two authors was to minimize the risk of errors due to different interpretations of the activities associated with the parts of the pre-movement phase.

In order to further improve the accuracy of categorisation of the observed behaviour and time for an individual more than one video recording, showing the same location was used for the assessment when possible.

3. Comparison of observed results and further analysis.

The categorisation of actions into the pre-movement parts and the observed pre-movement times by the two authors were compared. When the categorisation or the observed times differed, the experiment was viewed again by the two authors together before the final categorisation and pre-movement time was set.

4. Compilation of observed data.

The categorisation into the pre-movement parts and the measured pre-movement times (also separated into recognition time and response time) were compiled. Statistical distributions were fitted to the results using a statistical tool, @ Risk [34]. 
During the video analyses, the two parts of pre-movement time, according to the engineering model presented in Fig. 2, were identified separately. By treating the recognition time and the response time individually, it is possible to identify measures of importance related to reducing pre-movement times. Recognition and response times were determined by identifying actions linked to each of the two parts. The categorisation of actions for the two parts was done initially to provide a robust assessment. The different actions identifying any of the two parts are presented below in Table 2. The end of the response part, according to the engineering model, is when each occupant intentionally starts to move towards an exit.

After having performed an initial pilot study of video recordings, it was noted that people sometimes tend to go back and forth between the recognition and response parts. In real life evacuation, the transition between recognition and response is not as distinctive as in the engineering model. When this happened, an assumption was made that the response part started when the last distinctive recognition action ended.

The action ignoring the evacuation alarm can occur both during the recognition part and the response part of the pre-movement phase. Whether the person ignoring the evacuation alarm is unaware of the alarm (recognition part) or is choosing not to evacuate immediately (response part) was sometimes difficult to determine. When it was possible to follow and interpret the actions of the person, an assessment could be made. However, when the actions of the person were not clear the actions were counted as belonging to the recognition part and therefore increasing the recognition time on the expense of the response time. Potential impact on the results will be further elaborated in the discussion of the paper.

For the assessment of the data to statistical distributions, it was assumed that pre-movement times cannot adopt negative values and has no upper limit, only

\section{Table 2 \\ Activities Associated with Each Part of the Pre-movement Phase Used When Analysing Evacuation Experiments}

Response

Stop activity and be still

Listen

Looking around

Talk with people in the surroundings

See what others are doing

Search for further information

Be instructed by someone

Ignore the evacuation alarm ${ }^{\text {a }}$

Continue ongoing activity
Gather family and friends

Perform extinguishing attempt

Warn people in the surrounding

Talk with staff

Call emergency number

Gather belongings

Get familiar with the surroundings

Go to safe place in the building and wait for help Instruct others

Return to help someone/gather things

Help others

Ignore the evacuation alarm $^{\text {a }}$

\footnotetext{
${ }^{\mathrm{a}}$ For the recognition phase, ignoring the evacuation alarm means that the person does not react to the alarm or finish a task. For the response phase, ignoring the evacuation alarm means that the person has reacted to the alarm (already being identified as to have left the recognition part) but then chosen to ignore it
} 
distributions with these characteristics were selected as candidate distributions for the assessment. At this stage, distributions having the best fitting performance to the corresponding data set was selected. Akaike Information Criteria (AIC) was used as the main criteria when choosing fitted distributions. The AIC is a method suitable for ranking models to a set of data and is considered as appropriate when adapting statistical distributions to large sets of data [35, 36]. The AIC provides a relative ranking for the comparison between model and data.

\section{Results}

As mentioned in the previous section, recognition time, response time and total premovement time were determined through observation of the video recordings and using the identified activities related to the different phases according to the engineering model, see Table 2 . The results are presented as statistical distributions as well as with mean values, standard deviations and minimum and maximum values.

In total, recognition time, response time and total pre-movement time of 2486 individuals in the 40 unannounced, video recorded evacuation experiments were collected. The observations are distributed between the different occupancies as presented in Table 3. It should be noted that the statistical basis for cinemas are considerably larger (30 experiments) than for the other building occupancies indicating more reliable results in comparison to experiments with fewer data points and experiments.

All examined evacuation experiments were unannounced evacuations. None of the evacuees did get any prior information about the evacuation experiment. During the experiments, no other cue than the evacuation alarm was present.

In the classroom experiments, the teacher left the room before evacuation was initiated, leaving the students alone. The teacher was informed about the evacua-

\section{Table 3}

\section{Number of Observed Pre-movement Time Divided by Occupancy}

\begin{tabular}{|c|c|c|c|}
\hline Occupancy & $\begin{array}{l}\text { Number of obser- } \\
\text { vations }\end{array}$ & $\begin{array}{l}\text { Number of experi- } \\
\text { ments }\end{array}$ & $\begin{array}{l}\text { Origin of experi- } \\
\text { ments }\end{array}$ \\
\hline Office (alarm bell) & 45 & 1 & [32] \\
\hline Cinema (voice alarm) & 900 & 14 & {$[16,17,32]$} \\
\hline Cinema (siren) & 163 & 6 & {$[16,17]$} \\
\hline Cinema (alarm bell) & 886 & 10 & {$[16,32]$} \\
\hline Department store (voice alarm) ${ }^{\mathrm{a}}$ & 229 & 4 & {$[25,33]$} \\
\hline Restaurant/Café (voice alarm) ${ }^{\mathrm{a}}$ & 27 & 3 & [25] \\
\hline School (alarm bell) & 90 & 6 & [22] \\
\hline $\begin{array}{l}\text { Nightclub (evacuation assisted by staff, } \\
\text { voice alarm) }\end{array}$ & 62 & 1 & {$[28]$} \\
\hline $\begin{array}{l}\text { Nightclub (evacuation not assisted by } \\
\text { staff, siren) }\end{array}$ & 84 & 1 & [28] \\
\hline
\end{tabular}

${ }^{\text {a }}$ Prior to the public voice alarm, members of staff were alerted by a concealed message before the public alarm was initiated 
tion experiment. Having the teacher staying in the room when the evacuation alarm was activated would have introduced an unwanted form of influence on the students. All experiments are further explained in the references linked to each experiment.

Observed results are summarized in the tables below. In some experiments, recognition and response were not possible to identify separately. The results from these experiments are thus only presented as total pre-movement time. In Table 4, recognition times of the experiments are summarized. In Table 5, response times

\section{Table 4}

\section{Compilation of Observed Recognition Times for Different Occupancies}

\begin{tabular}{|c|c|c|c|c|}
\hline Occupancy & $\begin{array}{c}\text { Number of observa- } \\
\text { tions }\end{array}$ & Distribution (s) & $\begin{array}{c}\text { Mean }(\min -\max ) \\
(\mathrm{s})\end{array}$ & $\begin{array}{l}\text { SD } \\
(s)\end{array}$ \\
\hline Office & 37 & Loglogistic $(\beta=33.3 ; \alpha=2.9)$ & $40.6(6-111)$ & 27.4 \\
\hline $\begin{array}{l}\text { Cinema (voice } \\
\text { alarms) }\end{array}$ & 893 & $\begin{array}{l}\text { Loglogistic } \\
(\gamma=0 ; \beta=25.6 ; \alpha=5.3)\end{array}$ & $29.7(12-123)$ & 17.9 \\
\hline Cinema (siren) & 89 & $\begin{array}{l}\text { Loglogistic } \\
(\gamma=0 ; \beta=15.8 ; \alpha=6.9)\end{array}$ & $22.1(8-177)$ & 29.2 \\
\hline $\begin{array}{l}\text { Cinema (alarm } \\
\text { bell) }\end{array}$ & 880 & $\begin{array}{l}\text { Loglogistic } \\
(\gamma=0 ; \beta=16.1 ; \alpha=4.0)\end{array}$ & $19.0(4-209)$ & 16.1 \\
\hline Department store & 229 & $\begin{array}{l}\text { Lognormal } \\
(\mu=35.9 ; \sigma=10.4)\end{array}$ & $25.2(4-64)$ & 10.5 \\
\hline Restaurant/Café & 27 & Lognormal $(\mu=27.3 ; \sigma=9.9)$ & $27.3(13-56)$ & 9.9 \\
\hline School & 72 & $\begin{array}{l}\text { Lognormal } \\
(\mu=33.0 ; \sigma=52.0)\end{array}$ & $33.1(2-125)$ & 38.8 \\
\hline
\end{tabular}

Recognition times are presented as distributions, mean values, standard deviations and min-max values of the collected data. All times are in seconds

\section{Table 5}

\section{Compilation of Observed Response Times for Different Occupancies}

\begin{tabular}{|c|c|c|c|c|}
\hline Occupancy & $\begin{array}{c}\text { Number of observa- } \\
\text { tions }\end{array}$ & Distribution (s) & $\begin{array}{l}\text { Mean (min-max) } \\
(\mathrm{s})\end{array}$ & $\begin{array}{l}\text { SD } \\
(\mathrm{s})\end{array}$ \\
\hline Office & 37 & Exponential $(\beta=23.8)$ & $23.2(1-93)$ & 25.2 \\
\hline $\begin{array}{l}\text { Cinema (voice } \\
\text { alarms) }\end{array}$ & 891 & Gamma $(\alpha=3.5 ; \beta=4.2)$ & $14.4(1-50)$ & 7.5 \\
\hline Cinema (siren) & 89 & $\begin{array}{l}\text { Lognormal } \\
(\mu=8.2 ; \sigma=4.6)\end{array}$ & $7.9(1-19)$ & 4.3 \\
\hline Cinema (alarm bell) & 880 & Gamma $(\alpha=2.7 ; \beta=4.9)$ & $13.4(1-50)$ & 8.4 \\
\hline Department store & 229 & $\begin{array}{l}\text { Lognormal } \\
(\mu=11.2 ; \sigma=21.1)\end{array}$ & $10.6(1-81)$ & 13.7 \\
\hline Restaurant/Café & 27 & Weibull $(\alpha=1.5 ; \beta=27.9)$ & $25.1(2-70)$ & 17.6 \\
\hline School & 72 & Weibull $(\alpha=1.5 ; \beta=45.9)$ & $41.8(1-121)$ & 27.9 \\
\hline
\end{tabular}

Results are presented as distributions, mean values, standard deviations and min-max values of the collected data. All times are in seconds 


\begin{tabular}{|c|c|c|c|c|}
\hline Occupancy & $\begin{array}{l}\text { Number of observa- } \\
\text { tions }\end{array}$ & Distribution (s) & $\begin{array}{l}\text { Mean }(\min - \\
\max )(\mathrm{s})\end{array}$ & $\begin{array}{l}\text { SD } \\
(\mathrm{s})\end{array}$ \\
\hline Office & 45 & $\begin{array}{l}\text { Loglogistic } \\
(\gamma=0 ; \beta=52.5 ; \alpha=3.0)\end{array}$ & $64.4(12-201)$ & 45.6 \\
\hline $\begin{array}{l}\text { Cinema (voice } \\
\text { alarms) }\end{array}$ & 891 & $\begin{array}{l}\text { Loglogistic } \\
(\gamma=0 ; \beta=40.5 ; \alpha=5.8)\end{array}$ & $44.0(17-138)$ & 18.0 \\
\hline Cinema (siren) & 89 & Lognormal $(\mu=25.0 ; \sigma=6.2)$ & $30.0(14-179)$ & 28.1 \\
\hline Cinema (alarm bell) & 880 & $\begin{array}{l}\text { Loglogistic } \\
(\gamma=0 ; \beta=29.5 ; \alpha=5.0)\end{array}$ & $32.5(11-224)$ & 17.2 \\
\hline Department store & 229 & $\begin{array}{l}\text { Lognormal } \\
(\mu=35.9 ; \sigma=18.3)\end{array}$ & $35.9(5-111)$ & 17.7 \\
\hline Restaurant/Café & 27 & Weibull $(\alpha=3.8 ; \beta=58.1)$ & $52.5(20-86)$ & 15.7 \\
\hline School & 72 & $\operatorname{Gamma}(\alpha=3.0 ; \beta=24.5)$ & $74.9(13-170)$ & 42.3 \\
\hline $\begin{array}{l}\text { Night club (active } \\
\text { staff) }\end{array}$ & 62 & Weibull $(\alpha=2.7 ; \beta=52.5)$ & $46.6(11-87)$ & 18.7 \\
\hline $\begin{array}{l}\text { Night club (passive } \\
\text { staff) }\end{array}$ & 84 & $\begin{array}{l}\text { Loglogistic } \\
(\gamma=0 ; \beta=50.6 ; \alpha=2.3)\end{array}$ & $65.4(5-417)$ & 64.0 \\
\hline
\end{tabular}

Pre-movement times are presented as distributions, mean values, standard deviations and min-max values of the collected data. All times are in seconds

of the experiments are summarized. In Table 6, total pre-movement times of the experiments are summarized. All observed pre-movement times are compiled and presented in Fig. 3.

As the presented distributions are approximations of the true data it may be important to consider the accuracy of the predictions. In all cases, a range of possible candidate distributions were available and the selected represents the one having the best regression characteristics. In the following figures, examples of distributions are presented to illustrate common shapes. Chosen distributions show the results from the cinema experiments using a voice alarm. Also, the observed data are presented in the same diagrams. Even if there is a difference between the actual data and the selected distribution, the similarity between the two is obvious.

In order to further compare the data for each sample and the selected distribution the $\mathrm{p}-\mathrm{p}$ plot can be useful. The $\mathrm{p}-\mathrm{p}$ plot shows the probability distribution for the data and for the fitted distribution in the same diagram. Ideally, the $\mathrm{p}-\mathrm{p}$ plot would provide a straight line between 0,0 and 1, 1, indicating a perfect match between the data and the distribution. The $\mathrm{p}-\mathrm{p}$ plot may be used to qualitatively provide an indication of the goodness of the distribution fitting. In most cases a higher number of sample data points results in a better agreement between the probability distributions of data and fitted curve. Figures 4, 5 and 6 presents $\mathrm{p}-\mathrm{p}$ plots for the fitted curves and data for the corresponding Figs. 7, 8 and 9. The agreement between the fitted distribution curves and the corresponding data seem reasonable accurate. 


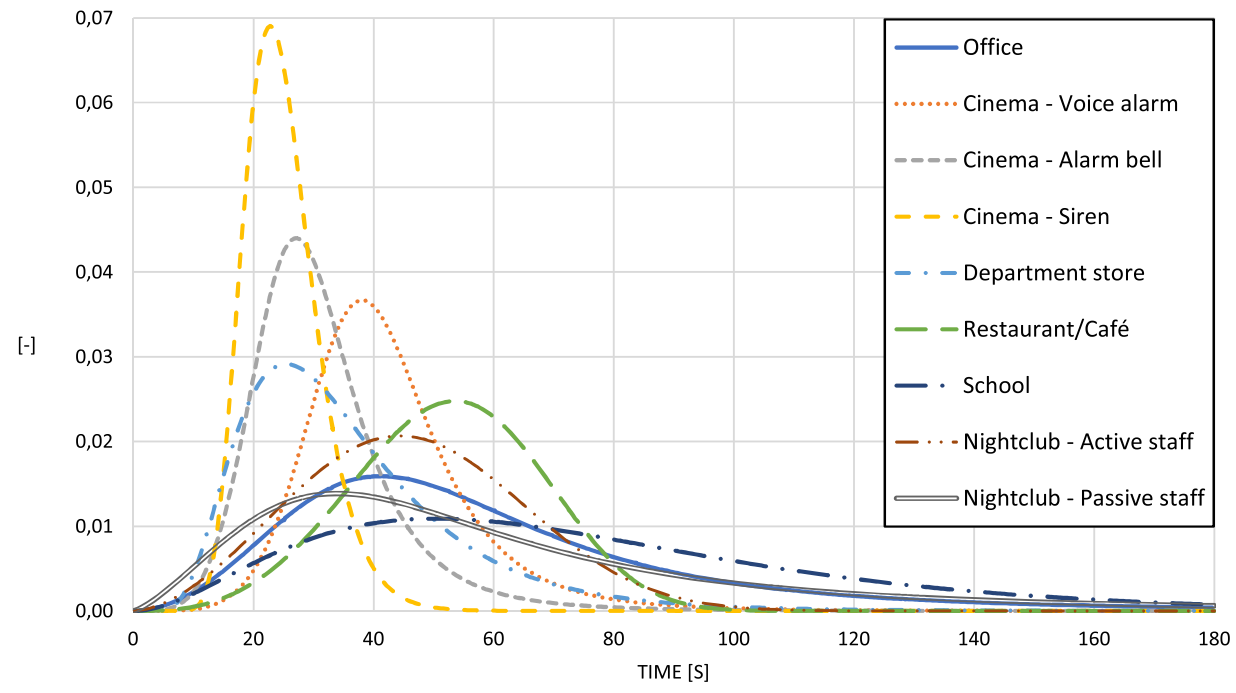

Figure 3. Probability distribution functions of all observed total pre-movement times in the study.

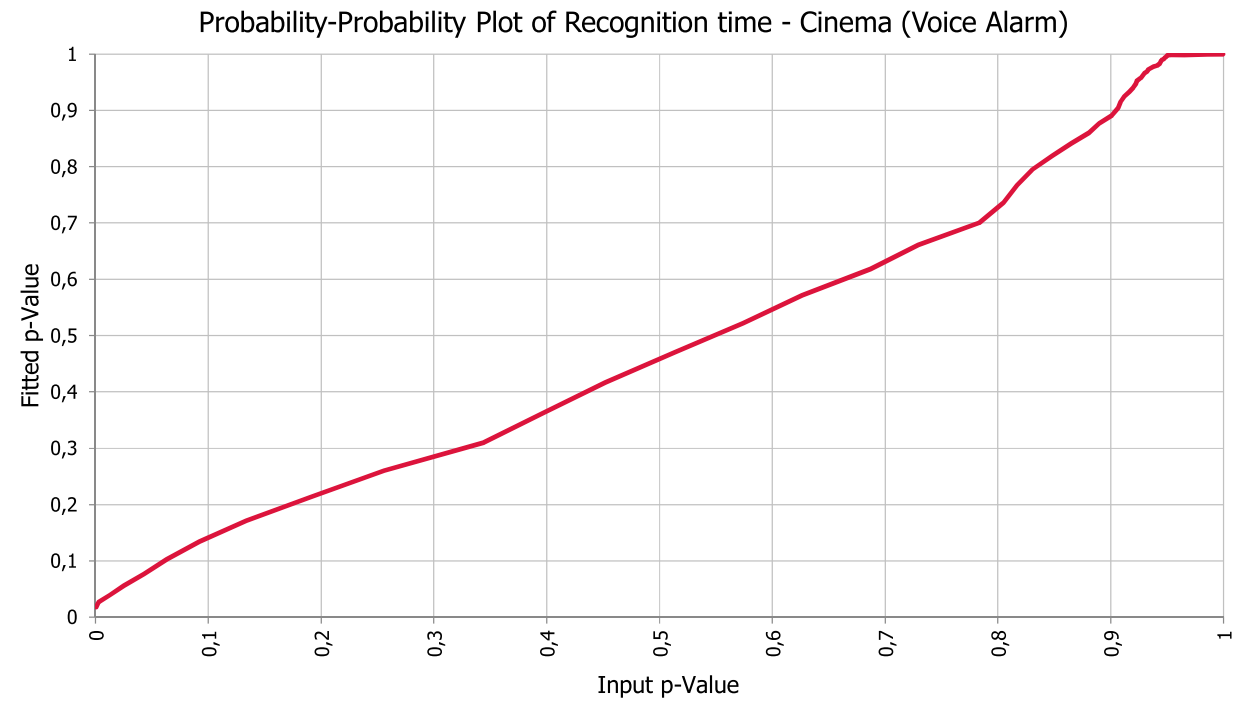

Figure 4. P-p plot for the recognition time for evacuation experiments in cinemas with the alarm type pre-recorded voice alarm. 
Probability-Probability Plot of Response time - Cinema (Voice Alarm)

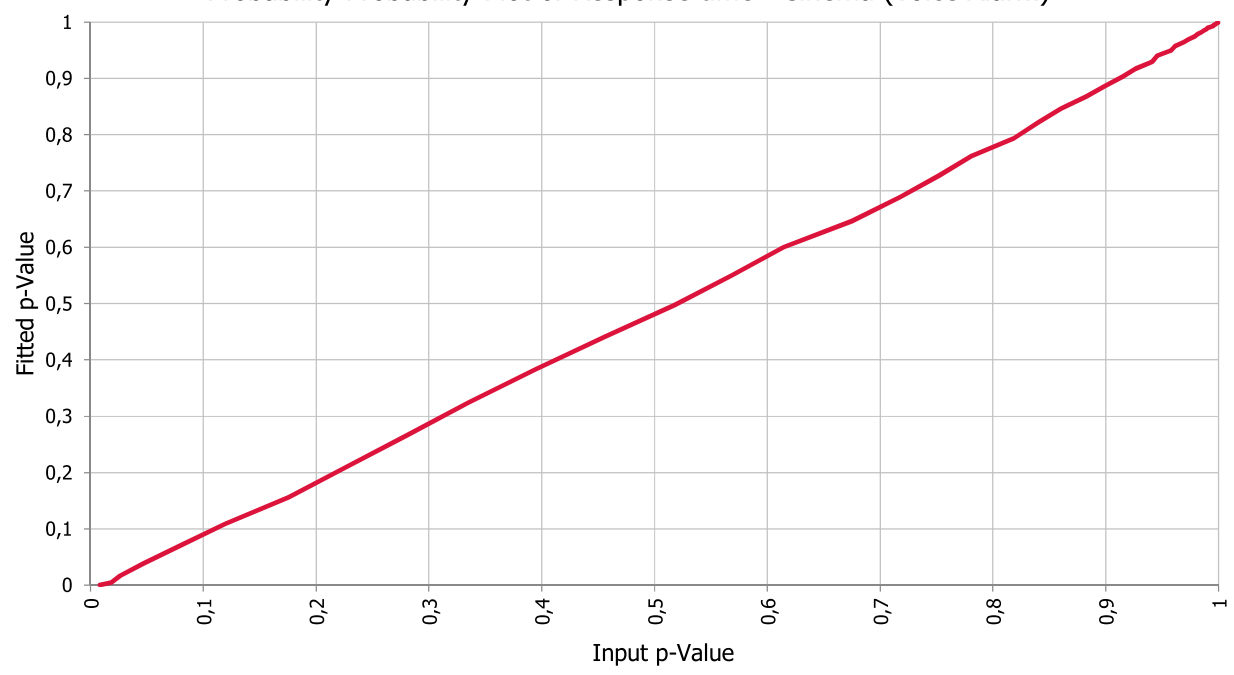

Figure 5. P-p plot for the response time for evacuation experiments in cinemas with the alarm type pre-recorded voice alarm.

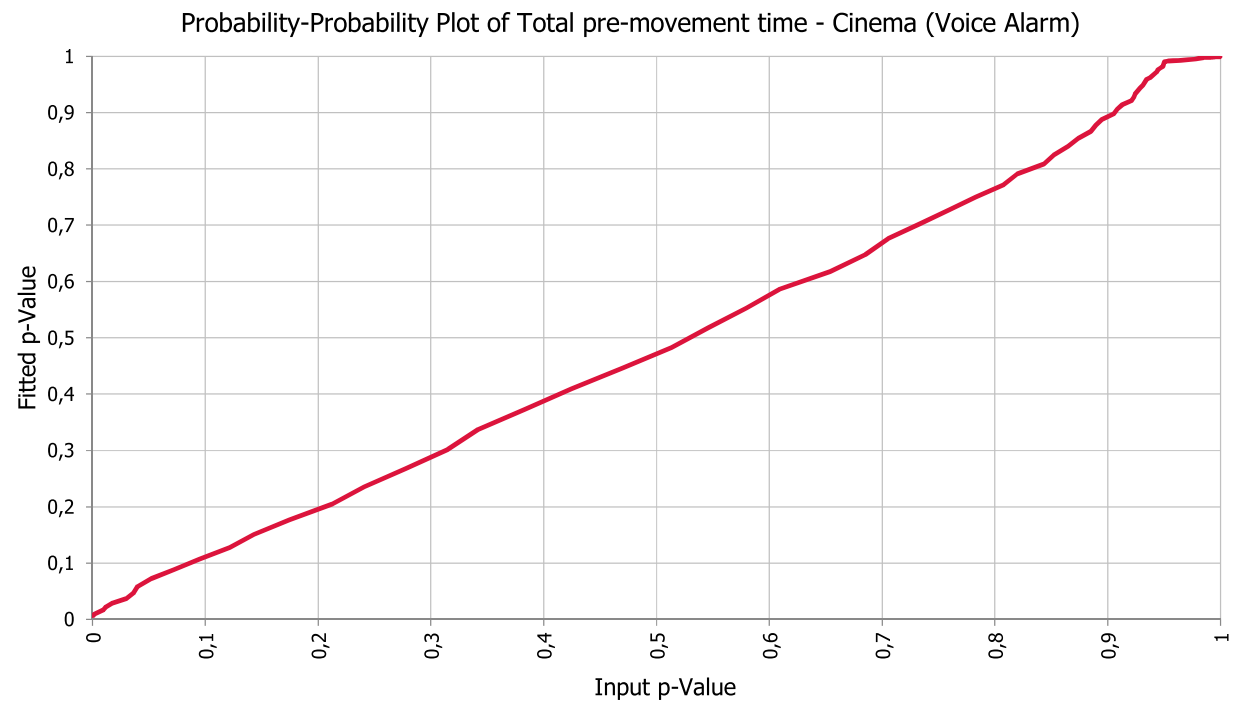

Figure 6. P-p plot for the total pre-movement time for evacuation experiments in cinemas with the alarm type pre-recorded voice alarm. 


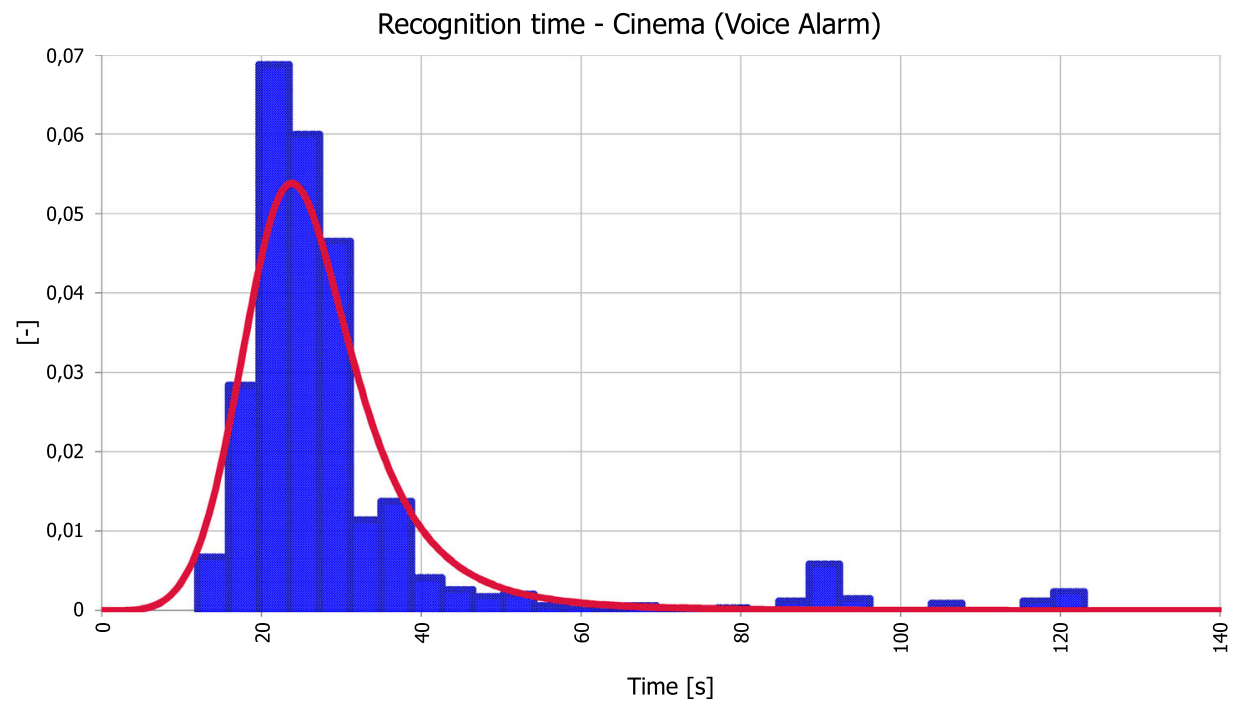

Figure 7. Histogram and fitted probability distribution regarding recognition time for evacuation experiments in cinemas with the alarm type pre-recorded voice alarm. Loglogistic distribution with the parameters $\gamma=0 ; \beta=25.6 ; \alpha=5.3$.

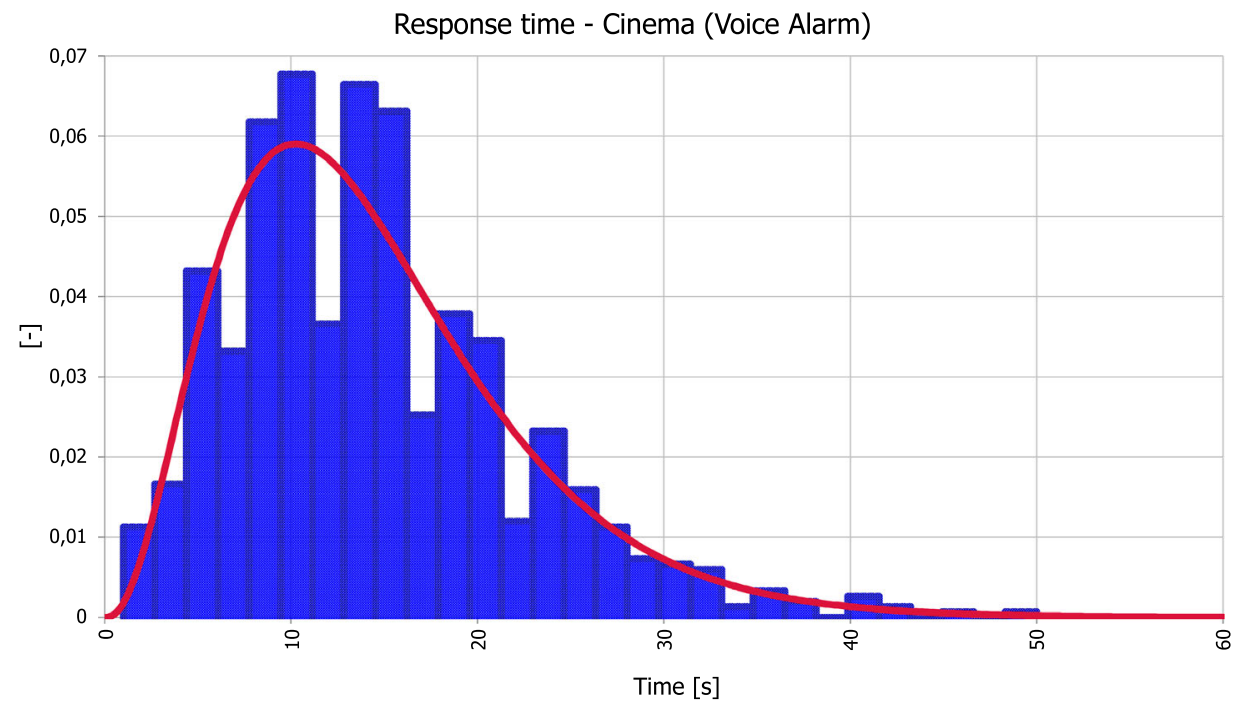

Figure 8. Histogram and fitted distribution regarding response time for evacuation experiments in cinemas with the alarm type prerecorded voice alarm. Gamma distribution with the parameters $\alpha=3.5 ; \beta=4.2$. 


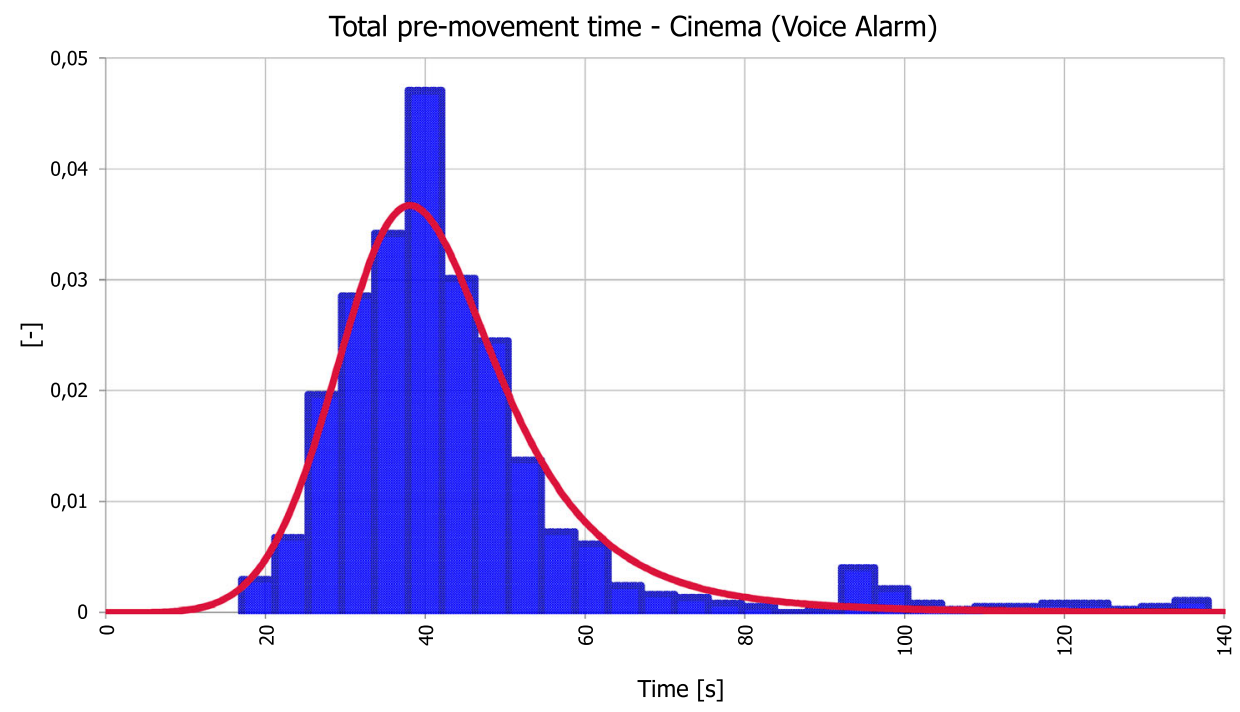

Figure 9. Histogram and fitted distribution regarding total premovement time for evacuation experiments in cinemas with voice alarm. Loglogistic distribution with the parameters $\gamma=0$; $\beta=40.5$; $\alpha=5.8$.

\section{Discussion}

In some of the observations of the video recordings, it was noted that people tend to go back and forth between the recognition and response phase. As previously mentioned in the paper it was assumed that the response part began when the last distinctive recognition action ended even if this implies that an error has been introduced. The assumption might have the impact on the result that the time for recognition actions are overestimated for some people. These assumptions could have been avoided if interviews with the evacuating persons could have been performed to get a more accurate prediction of when the different parts ended and started. Obviously, this was not possible due to the nature of the assessment using previously recorded films. However, the relation between recognition time and response time does not affect the total pre-movement time.

For some observed persons, it was difficult to determine whether or not the persons stood in a queue or if they were just waiting for someone before moving together towards an exit. Queuing and waiting for friends or family are (according to the analysis template used in this study) activities that belong to different phases during building evacuation. Waiting for friends or family is an activity that is estimated to belong to the response part while queuing belongs to the movement phase. The judgement on when a person enters a queue could, of course, affect the pre-movement time and in some cases only an interview with the specific person could solve this uncertainty. 
Some persons in the experiments did not finish their response actions before the experiment ended. The established pre-movement time for these people have been assumed based on observations from other people in the same experiment that were at the same or nearby location. The time added for these cases were in the order of 5 to $10 \mathrm{~s}$. This is, of course, a source of error when the total pre-movement time becomes an assumption rather than based on an actual observation. However, this behaviour was not common and is judged to have little influence on the total response time.

When performing a regression analysis, outliers are often excluded to obtain a better fit to distributions. In this study, outliers have not been excluded from the data. High outliers will, however, result in a slightly conservative estimate of the distribution of pre-movement time. This may be considered in a practical application of the presented data and distributions.

A problem when performing the video analysis was the, in some cases, limited video coverage of the building, especially for the larger buildings such as for department stores. The goal with this study has been to determine the pre-movement time and its component parts recognition and response, which makes it crucial to be able to follow a person from the time when the evacuation alarm starts until a distinct movement towards an exit begins. This means that the pre-movement time cannot be determined for persons that enter the camera view after the recognition phase has ended, nor can it be determined for persons that disappear from the camera view without having completed the response phase. This means that some persons appearing in the videos have not been included in the analysis.

As previously mentioned, a combination of ranking methods is used to verify which distributions fit the data. This is done in order to get an overview of which distribution that fit the data that were obtained from the video analysis. However, different ranking methods should be used for different situations. For example, Chakrabarti and Gosh [37] describes that the Bayes Information Criterion is best suited for fitting models that are based on data, and the Akaike Information Criterion is best suited for models where future data should be expected. Both selection criteria are relevant for this study and a combination of the ranking methods are therefore used as a weighted benchmark. Regardless of which distribution is chosen, it will always be a simplification of reality and thereby loss of information. This must be acknowledged by the user of the data provided in this paper.

Depending on occupancy and alarm type, variations regarding the duration of recognition time and response time were observed. The recognition time varies somewhat between different alarm types and between occupancies. The highest mean value for the recognition time was found in the office experiment, i.e. approximately $40 \mathrm{~s}$. This might be because people tend to ignore the alarm initially in order to complete the task that they were working with. It is, however difficult to judge this as little information is available about activities performed while the persons were in their office rooms, as the observation cameras were located in the corridor outside the office rooms. The relation between actions performed in the recognition part and in the response part is therefore subjected to higher uncertainty. 
The second longest recognition time was observed in the university lecture room experiments. The students sometimes continued working on their tasks before showing any signs of realization that it was an alarm sounding in the classroom. However, it is uncertain if these students had noticed the evacuation alarm but ignored it in order to finish a task or if they did not notice the alarm. Depending on the realization of the alarm, this part of the pre-movement time can belong to either the recognition part or the response part of the phase of evacuation. When it was not possible to interpret the actions of the person, ignoring the evacuation alarm was included in the recognition part of pre-movement time.

Both the recognition time and the response time depends on social influence. Persons tend to observe what their friends and other people in the building are doing. If the other people's reactions do not match with the response that a person considers appropriate after hearing the alarm, it might lead to a new recognition phase. This was observed in some of the cinema and university experiments. Persons that started to prepare for evacuation early stopped and sat down again because the rest of the people in the building did not initiate the evacuation at that time. Persons with short recognition times often have longer response times. During the video analysis, it was observed that persons reacting quickly to an alarm often had to wait for others. Even though the total pre-movement time is the same for persons in a group, the individual recognition time and response time might differ between individuals.

As mentioned earlier in the paper, the observations are made from previously performed evacuation experiments. The quality of the video resolution, observation angles and the overall quality of the experiments varies depending on occupancy and to which specific experiment the video recording belongs to. When estimating the quality of the observed results, the cinema experiments are assessed to be the best. The angle of the camera gave an overview of the cinema theatre leading to a better possibility to assess the behavior of people. Further, the results are based on 30 different experiments divided between two separate experimental series making the results more trustworthy since it minimizes the risk of observing experiments with results with extreme (short or long) pre-movement time. In the same way, restaurant and office results are more uncertain since results are based on fewer observations and experiments. Regarding the office experiments, the results are associated with higher uncertainty as it, as just mentioned, sometimes was not possible to see a person during the pre-movement phase of evacuation.

The dependency of the observed pre-movement times will to some extent create a problem when assigning the data to a statistical distribution, i.e. the data points are not independent. This is a methodological problem as a probability derived from a distribution is supposed to be independent of others in the same location. This is, however, a typical problem when assessing dependent data, but the results will still represent the population time distribution. If social influence occurs during an evacuation, it will have an effect on the expected pre-movement time distribution. Therefore, the results may be considered valid in cases where one could expect to see similar behaviour as in the experiments. As the experiments were performed as unannounced evacuation similar behavioural patterns may be expected in also other evacuations for similar occupancies. 
Similarly, the results are affected by the time when the first person responds in a room with several persons, like in a cinema. The time it takes for the first person to respond clearly differs between experiments, not much, but still there is a difference. An alternative presentation approach could be to normalize the distributions with respect to the first person's response time. This was, however, not done due to the reason of knowing if the results would be any better as the number of experiments still is low.

The response time varies considerably between the different experiments. The length of this part depends on several parameters. One parameter that affect the response time is the occupancy type. For example, the response time for offices and universities are quite long. This might be because of the earlier mentioned commitment to a task. Another occupancy that had a long response time was the restaurant/café. It was observed that people did not seem to be willing to leave food or beverages that they had already paid for.

The other occupancies had shorter response times, i.e. the cinemas, and the department stores. The response time in the cinema experiments consisted of people gathering their belongings and waiting for their company. In the department stores, people tended to return merchandise, wait for their company and to find out where to go.

Other parameters that might affect the response time are season and weather condition. People might not wear jackets in the summer, which means that they do not have to collect these before evacuating, resulting in shorter response times. Regarding the weather conditions, people might not be that keen on evacuating if it is cold or rainy outside. This has, however, not been examined in the present study.

It can be noted that the number of different distributions fitted to the observed data is larger for the response time compared to the recognition time. This might be because the number of possible actions for the response phase are larger than for the recognition phase, as can be seen in Fig. 1. The response phase is more complex and dependent on the current situation. The response phase of the premovement time is a phase that depends on many different factors which contribute to increased uncertainty when performing an evacuation analysis.

A homogeneity amongst the analyzed occupancies is observed. For instance, all studied department stores are relatively large. The results for the larger department stores could be valid for smaller department stores too, but it would have been interesting to compare the results in order to investigate differences. Another limitation is that for some of the occupancies, only one or a few experiments were carried out. For example, the nightclub results are based on only two experiments, each having different conditions with respect to involvement by the members of staff. This is also the case for the department store experiments, where only one experiment was carried out for each store. It would be of interest to study several experiments at the same location in order to see how the results differ, as Bayer and Rejnö [16] did in the cinema evacuation experiments. They did 18 experiments in the same premises examining six different evacuation alarm types.

A general limitation of this study is that all the analyzed occupancies, except cinemas, have less than 100 observations. This means that the results for these 
experiments are more uncertain. More data from different experiments are required in order to gain certain results and more representative distributions.

At two of the cinema experiments with pre-recorded evacuation messages performed by Reinicke [17] there were problems with the alarm. The first sequence in the recordings was incomplete for these experiments. This could affect the course of events as it takes longer time for the visitors to get the information in the message. It could also affect the credibility of the alarm/message. An incomplete message could be interpreted as a malfunction of the alarm or that the experiment could be a fire drill. If the alarm had functioned as it was supposed to, the premovement time for these two experiments might have been shorter.

In some experiments in the classrooms, the students clearly ignored the alarm and did not take it seriously. This behavior could be explained by the fact that the alarm bell that was located in the classroom did not sound. The sound from the alarm came from the corridor outside the classroom. The students in the classroom might have thought that the alarm did not concern them or that it was due to a fire drill. There were not any other signs of a fire when a student checked the corridor. This student came back into the classroom and sat down again. By excluding the result of this particular experiment, the mean value is affected to a lower value. However, if there should have been other signs of a fire, the response would certainly be different.

It was observed that some persons did not evacuate in spite of an active fire alarm and evacuating persons in the building. The cause of this behavior is difficult to determine. In the experiments performed by Bayer and Rejnö [16], some people sat down in their chairs until the alarm stopped. It might be because they did not take the alarm seriously or that they were waiting for the exit queues to decrease in size. This behavior was also observed in the cinema experiments in [17]. Some persons endured the ongoing alarm by covering their ears instead of leaving the building. The pre-movement times for these people were either assumed (if possible) or the data points were excluded. These pre-movement times are, by not excluding the extreme values from the data, represented as the tails in the distributions.

\section{Conclusions}

The large amount of data on evacuation activities provided lead to a quantification of statistical distributions for recognition time, response time and the sum, i.e. the total pre-movement time. In most cases the data was fitted to either a lognormal or a loglogistic distribution.

The response time is a more complex part of the pre-movement time. For the response time, a larger number of candidate distributions were fitted to the observed data than for recognition time and total pre-movement time.

The developed scheme for assessing pre-movement activities was useful and may be used for future assessment.

The duration of the parts of pre-movement times depends on the type of occupancy. In some occupancies, recognition constitutes the greater part of pre-move- 
ment time and in other occupancies the response time lasted longer. No general tendencies were observed in the study.

The role of the person, occupation activity, type of evacuation alarm and social influence of people in the surroundings are examples of aspects that are believed to affect the pre-movement time.

\section{Acknowledgements}

The authors would like to thank Klas Bayer, Tobias Rejnö, Erik Sävmark, Joachim Holmström, Boel Reinicke, Marie Lundqvist, Katja Månsson, Roni Nasr, Magnus Wall and others contributing to this study by performing evacuation experiments. The entire set of data is available in a spread sheet format at https://lup.lub.lu.se/student-papers/search/publication/8917982.

\section{Open Access}

This article is distributed under the terms of the Creative Commons Attribution 4.0 International License (http://creativecommons.org/licenses/by/4.0/), which permits unrestricted use, distribution, and reproduction in any medium, provided you give appropriate credit to the original author(s) and the source, provide a link to the Creative Commons license, and indicate if changes were made.

\section{References}

1. Canter D, Breaux J, Sime J (1980) Domestic, multiple occupancy, and hospital fires. In: Canter D (ed) Fires and human behaviour Wiley, Chichester, pp 117-136

2. Canter D (1980) Fires and human behaviour: an introduction. In: Canter D (ed) Fires and human behaviour, 1st edn. Wiley, Chichester

3. Gwynne SMV, Kuligowski ED, Kinsey MJ (2015) Human behaviour in fire-model development and application. In: Proceedings of the 6th international symposium on human behaviour in fire. Downing College, Cambridge, UK, 28th-30th September 2015. Interscience Comm, pp 23-34

4. Sime JD (2001) An occupant response shelter escape time (ORSET) model. Saf Sci 38:109-125

5. Proulx G (2007) Response to fire alarms. Fire Prot Eng 33:8-14

6. Nilsson D, Johansson A (2009) Societal influence during the initial phase of a fire evacuation - analysis of evacuation experiments in a cinema theatre. Fire Saf J 44:71-79

7. Zhang J, Song W, Xu X (2008) Experiment and multi-grid modelling of evacuation from a classroom. Physica A 387:5901-5909

8. Galea E, Deere S, Hopkin C, Xie H (2017) Evacuation response behaviour of occupants in a large theatre during a live performance. Fire Mater 41:467-492

9. Sime J (1985) Movement toward the familiar: person and place affiliation in a fire entrapment setting. Environment and Behaviour 17(6):697-724

10. Proulx G (2003) Playing with fire: understanding human behavior in burning buildings. ASHRAE J 45(7):33-35 
11. Sime JD (1980) The concept of 'panic'. In: Canter D (ed) Fires and human behaviour Wiley, Chichester, pp 63-81

12. Sime J, Kimura M (1988) The timing of escape: Exit choice behaviour in fires and building evacuation. In: Sime J (ed) Safety in the built environment E \& F.N Spon, London

13. Tong D, Canter D (1985) The decision to evacuate: a study of the motivations which contribute to evacuation in the event of fire. Fire Saf J 9:257-265

14. Shields JT, Boyce K (2000) A study of evacuation from large retail stores. Fire Saf J 35:25-49

15. Proulx G, Sime JD (1991) To prevent 'panic' in an underground emergency: why not tell people the truth? In: Cox G, Langford B (eds) Proceedings of the third international symposium on fire safety science. Elsevier, London, pp 843-852

16. Bayer K, Rejnö T (1999) Utrymningslarm: Optimering genom fullskaleförsök-Evacuation alarm, Optimizing through full-scale experiments. Department of Fire Safety Engineering, Lund University, Lund

17. Reinicke B (2007) Utrymning från biograf: Resultat från fullskaleförsök-Cinema evacuation: Results from full-scale experiments. Department of Fire Safety Engineering, Lund

18. Holmström J, Sävmark E (2013) Talat utrymningsmeddelande: optimerad utformning utifrån fullskaleförsök - Pre-recorded evacuation message: optimized design via unannounced evacuation experiments. Department of Fire Safety Engineering and Systems Safety, Lund University, Lund

19. D'Orazio M, Bernardini G (2012) An Experimental study on the correlation between "attachment to belongings" "pre-movement" time. In: Weidmann U, Schreckenberg M, Kirsch U (eds) Pedestrian and evacuation dynamics Springer, Cham, pp 167-178

20. Gwynne S, Boyce K (2016) Engineering data. In: Hurley M, Gottuk D, Hall J Jr, Harada K, Kuligowski E, Puchovsky M, Wieczorec C (eds) SFPE handbook of fire protection engineering, 1th edn. Society of Fire Protection Engineers, Quincy, pp 2429-2551

21. Frantzich H, Nilsson D, Rød K (2016) Utrymning och tekniska installationer i vägtunnlar med dubbelriktad trafik-Evacuation and technical installations in single tube road tunnels (Research Report; Nr. 3199). Brandteknik LTH, Lund

22. Nilsson D (2006) Utformning av talade utrymningsmeddelanden-Erfarenheter från en enkätundersökning och oannonserade utrymningsförsök; Design of pre-recorded fire evacuation messages-Experiences gained from a questionnaire study and unannounced evacuation experiments. Department of Fire Safety Engineering, Lund University, Lund

23. Purser D, Bensilum M (2001) Quantification of behaviour for engineering design standards and escape time calculations. Saf Sci 38:157-182

24. Sandberg A (1997) Unannounced evacuation of large retail-stores: An evaluation of human behaviour and the computer model Simulex. Department of Fire Safety Engineering, Lund University, Lund

25. Frantzich H (2001) Occupant behaviour and response time-results from evacuation experiments. In: 2nd international symposium on human behaviour in fire-understanding human behaviour for better fire safety design - conference proceedings. Interscience Communications Limited, Cambridge, pp 159-165

26. Proulx G (1995) Evacuation time and movement in apartment buildings. Fire Saf $\mathbf{J}$ 24:229-246

27. Proulx G, Fahy R (1997) The time delay to start evacuation: review of five case studies. In: Hasemi Y (ed) Fire safety science: proceedings of the fifth international symposium International Association for Fire Safety Science, Melbourne, pp 783-794 
28. Nasr R, Wall M (2012) Utrymning av nattklubb: Resultat från två fullskaleförsök-Nightclub evacuation: Results from two full-scale experiments. Department of Fire Safety Engineering, Lund University, Lund

29. Fahy RF, Proulx G (2001) Toward creating a database on delay times to start evacuation and walking speeds for use in evacuation modelling. National Research Council Canada, Ottawa

30. Proulx G (2002) Movement of people: the evacuation timing. In: DiNenno PJ, Drysdale D, Beyler CL, Walton DW, Custer RL, Hall JR, Watts JM (eds) SFPE handbook of fire protection engineering NFPA, Quincy, pp 3:343-3:366

31. Kuligowski E (2013) Predicting human behavior during fires. Fire Technol 49:101-120

32. Nilsson D, Frantzich H (2007) Vägval vid utrymning: utrymningsförsök med gröna lampor vid nödutgångar-Exit choice and evacuation: unannounced evacuation experiments with green flashing lights at emergency exits. Department of Fire Safety Engineering, Lund University, Lund

33. Lundqvist M, Månsson K (2006) Revision av ledningssystem för brandskydd-Audit of fire protection management system. Department of Fire Safety Engineering, Lund University, Lund

34. Palisade Corporation (2016) User's guide @ risk—risk analysis and simulation add-in for Microsoft Excel, Version 7. Palisade Corporation, Ithaca

35. Forster M, Sober E (2011) AIC scores as evidence: a Bayesian interpretation. In: Bandyopadhyay PS, Forster M (eds) Philosophy of statistics: handbook of the philosophy of science, vol 7. Elsevier, Amsterdam, pp 535-549

36. Norton JD (2011) Challenges to Bayesian confirmation theory. In: Bandyopadhyay PS, Forster MR (eds) Philosophy of statistics: handbook of the philosophy of science, vol 7. Elsevier, Amsterdam, pp 391-439

37. Chakrabarti A, Ghosh JK (2011) AIC, BIC and recent advances in model selection. In: Bandyopadhyay P, Forster MR (eds) Philosophy of statistics: handbook of the philosophy of science, vol 7. Elsevier, Amsterdam, pp 583-605

Publisher's Note Springer Nature remains neutral with regard to jurisdictional claims in published maps and institutional affiliations. 